\title{
Incidence of Hepatocellular Carcinoma in Patient with Elevated Alpha Fetoprotein before DAAS
}

\author{
Ahmed Mohamed Mansour Abd El Shafi, Abd El Wehab Fathi Ali, Mohammed Fakhery Mohamed Morsey \\ Department of Hepatology, Gastroenterology and Infectious Diseases, Faculty of Medicine, \\ Al-Azhar University (Assiut), Egypt. \\ *Corresponding author: Ahmed Mohamed Mansour Abd El Shafi, Mobile: (+20) 01002159714, \\ E-Mail: ahmedserag932@yahoo.com
}

\begin{abstract}
Background: Management of chronic infection with hepatitis C virus (HCV) with direct acting antivirals (DAAs) agents achieves high virological response. Recently, there is a matter of controversy about occurrence of hepatocellular carcinoma (HCC) following those agents. Objective: This study aimed to evaluate the efficacy of alpha fetoprotein (AFP) in development of HCC following DAAs therapy. Patients and methods: two hundred patients with chronic HCV infection who were eligible for DAAs therapy were recruited. Those patients were followed up for one year following therapy to detect development of HCC. Patients were grouped into either with normal AFP (100 patients) or high AFP (100 patients). Results: Majority (84\%) of patients were males with overall mean age of $43.87 \pm 12.76$ years. There were no significant differences between both groups of patients as regard baseline data. With exception of $4 \%$ of patients, all of them reached the sustained virological response (SVR). Frequency of HCC detection was higher among those patients with high AFP $(9(9 \%)$ vs $1(1 \%) ; \mathrm{P}<0.001)$. We found that liver cirrhosis; FIB-4, APRI and AFP were predictors for HCC. AFP had the best diagnostic accuracy for prediction of HCC following DAAs

Conclusion: Patients who received DAAs for HCV infection should be regularly screened for development of HCC.

Keywords: Hepatocellular carcinoma, Alpha fetoprotein, Direct acting antivirals.
\end{abstract}

\section{INTRODUCTION}

Progression to liver cirrhosis and development of hepatocellular carcinoma (HCC) are the major complications of hepatitis $\mathrm{C}$ virus (HCV) infection. Pathophysiological mechanism to develop HCC and its progression till metastasis is considered a complex process. This process required long term interaction between the viral components and defense mechanism of the host ${ }^{(1)}$. Sofosbuvir (SOF) is one of the new direct acting antivirals (DAAs) that could be used with other agents belong to DAAs and produce high safety profile and efficacy. Its tolerability and efficacy was proofed whatever age, sex, HCV genotype and stage of hepatic fibrosis ${ }^{(2)}$.

Alpha-fetoprotein (AFP) is released form gestational sac in the early embryonic life then liver synthesize it later on. Its high level in cirrhotic patients carries a risk for $\mathrm{HCC}^{(3)}$. This work was conducted to assess the predictive value of baseline AFP in prediction of HCC following DAAs therapy.

\section{PATIENTS AND METHODS}

A cross sectional study was conducted in period between 2020 and 2021 at Outpatients Clinics, Al-Azhar University Hospitals. Based on previously reported HCC following DAAs therapy that was $2.69 \%$ (4) with considering $3 \%$ alpha error and $95 \%$ confidence interval, a minimum of 112 patients receiving DAAs were required.

Two hundreds patients with HCV infection who were eligible for direct acting antivirals (DAAs) were enrolled. Any patient with one or more of the following criteria was excluded; patients aged $<18$ years, platelet count less than $5000 / \mathrm{mm}^{3}$, extra hepatic malignancy, pregnancy or inability to use effective contraception, inadequately controlled diabetes mellitus (glycosylated hemoglobin more than $9 \%$ ), and/or patient's refusal

Those enrolled patients were subdivided based on baseline level of alpha fetoprotein into ${ }^{(5)}$ : One hundred patients with normal AFP $(<10 \mathrm{ng} / \mathrm{ml})$, and one hundred patients with high AFP $(\geq 10 \mathrm{ng} / \mathrm{ml})$.

Complete history taking and clinical assessment were done. The following data were gathered; age, sex, body mass index, previous interferon therapy for $\mathrm{HCV}$ infection, residence, and comorbidities as diabetes mellitus, hypertension, ischemic heart disease and chronic kidney disease.

\section{Laboratory tests and serum biomarkers:}

The investigations that were ordered are complete blood picture, liver function tests, kidney function tests including blood urea and serum creation. Also, baseline AFP was assessed in all patients. Different markers of fibrosis were assessed at baseline during follow up; the AST to platelet ratio index (APRI) score and Fibrosis-4 (FIB-4) score. Abdominal ultrasonography was performed in all patients at baseline and SVR24 for the detection of focal lesions and hepatic decompensation. Screening for HCC development occurred every three months till one year after end of therapy by abdominal ultrasound. Any suspected lesion during follow up, a dynamic imaging either computed tomography and/or magnetic resonance image would be done.

\section{Ethical consideration:}

Approval of the study was obtained from the

Research Ethics Committees in Faculty of Medicine, 
Al-Azhar University and it was conducted in accordance with the Code of Good Practice and the guidelines of Declaration of Helsinki, $7^{\text {th }}$ revision, 2013. All patients were informed about the study and a written consent was obtained from each patient.

\section{Statistical analysis}

Data were collected and analyzed those using

SPSS (Statistical Package for the Social Sciences, version 20, IBM, and Armonk, New York). Continuous data were expressed in form of mean $\pm \mathrm{SD}$ and compared with Student t test while nominal data were expressed in form of frequency (percentage) and compared with $C h i^{2}$ test. Predictors for development of HCC following DAAs therapy were determined by multivariate regression tests, Level of confidence was kept at $95 \%$ and hence, $P$ value was considered significant if $<0.05$.

RESULTS

Baseline data of enrolled patients (Table 1):

Both groups of patients had insignificant differences as regard baseline data.

Table (1): Baseline data of enrolled patients

\begin{tabular}{|c|c|c|c|}
\hline & $\operatorname{High}$ AFP $(n=100)$ & Normal AFP $(n=100)$ & $P$ value \\
\hline Age (year) & $44.98 \pm 12.87$ & $42.22 \pm 16.87$ & $>0.05$ \\
\hline $\begin{array}{l}\text { Sex } \\
\text { Male } \\
\text { Female }\end{array}$ & $\begin{array}{l}89(89 \%) \\
11(11 \%)\end{array}$ & $\begin{array}{l}79(79 \%) \\
21(21 \%)\end{array}$ & $>0.05$ \\
\hline BMI $\left(\mathrm{kg} / \mathrm{m}^{2}\right)$ & $24.09 \pm 4.87$ & $25.89 \pm 6.09$ & $>0.05$ \\
\hline $\begin{array}{l}\text { Residence } \\
\text { Rural } \\
\text { Urban }\end{array}$ & $\begin{array}{l}78(78 \%) \\
22(22 \%) \\
\end{array}$ & $\begin{array}{l}81(81 \%) \\
19(19 \%) \\
\end{array}$ & $>0.05$ \\
\hline $\begin{array}{l}\text { Occupation } \\
\text { None } \\
\text { Housewife } \\
\text { Employee } \\
\text { Student }\end{array}$ & $\begin{array}{c}68(68 \%) \\
11(11 \%) \\
12(12 \%) \\
9(9 \%)\end{array}$ & $\begin{array}{c}65(65 \%) \\
15(15 \%) \\
9(9 \%) \\
11(11 \%)\end{array}$ & $>0.05$ \\
\hline Diabetes mellitus & $14(14 \%)$ & $16(16 \%)$ & $>0.05$ \\
\hline Hypertension & $5(5 \%)$ & $7(7 \%)$ & $>0.05$ \\
\hline Ischemic heart disease & $2(2 \%)$ & $1(1 \%)$ & $>0.05$ \\
\hline INF experienced & $7(7 \%)$ & $10(10 \%)$ & $>0.05$ \\
\hline Smoker & $18(18 \%)$ & $21(21 \%)$ & $>0.05$ \\
\hline
\end{tabular}

Data expressed as frequency (percentage), mean (SD). AFP: alpha fetoprotein; INF: interferon

Baseline laboratory data among enrolled patients (Table 2):

There was a significantly higher platelets count among those with normal AFP. Patients with high AFP had significantly higher FIB-4 and APRI.

Table (2): Baseline laboratory data of enrolled patients

\begin{tabular}{|l|c|c|c|}
\hline & High AFP $(\mathbf{n}=\mathbf{1 0 0})$ & Normal AFP $(\mathbf{n}=\mathbf{1 0 0})$ & $\boldsymbol{P}$ value \\
\hline HCV RNA $\left(10^{6} \mathrm{u} / \mathrm{l}\right)$ & $1.23 \pm 0.10$ & $1.11 \pm 0.18$ & $>0.05$ \\
\hline Hemoglobin $(\mathrm{gm} / \mathrm{dl})$ & $12.76 \pm 1.87$ & $12.99 \pm 2.98$ & $>0.05$ \\
\hline Platelets $\left(10^{3} / \mathrm{ul}\right)$ & $155.78 \pm 33.87$ & $216.98 \pm 22.22$ & $<\mathbf{0 . 0 0 1}$ \\
\hline Leucocytes $\left(10^{3} / \mathrm{ul}\right)$ & $5.91 \pm 1.33$ & $6.01 \pm 1.87$ & $>0.05$ \\
\hline Bilirubin $(\mathrm{mg}) \mathrm{dl}$ & $1.01 \pm 0.11$ & $0.99 \pm 0.17$ & $>0.05$ \\
\hline Albumin $(\mathrm{mg} / \mathrm{dl})$ & $4.01 \pm 1.11$ & $39.80 \pm 2.01$ & $>0.05$ \\
\hline AST $(\mathrm{u} / \mathrm{l})$ & $66.78 \pm 10.14$ & $69.01 \pm 14.22$ & $>0.05$ \\
\hline ALT $(\mathrm{u} / \mathrm{l})$ & $68.13 \pm 5.66$ & $70.01 \pm 6.09$ & $>0.05$ \\
\hline Creatinine $(\mathrm{mg} / \mathrm{dl})$ & $1.11 \pm 0.10$ & $1.09 \pm 0.10$ & $>0.05$ \\
\hline Urea $(\mathrm{mg} / \mathrm{dl})$, & $4.22 \pm 0.54$ & $4.89 \pm 1.45$ & $>0.05$ \\
\hline INR & $1.03 \pm 0.03$ & $1.04 \pm 0.02$ & $>0.05$ \\
\hline FIB-4 & $4.64 \pm 1.34$ & $2.55 \pm 0.98$ & $<\mathbf{0 . 0 0 1}$ \\
\hline APRI & $6.65 \pm 1.11$ & $3.51 \pm 0.12$ & $\mathbf{0 . 0 1}$ \\
\hline U/S evaluation & & & \\
Liver cirrhosis & $76(76 \%)$ & $12(12 \%)$ & $<\mathbf{0 . 0 0 1}$ \\
Splenomegaly & $30(30 \%)$ & $10(10 \%)$ & $<\mathbf{0 . 0 0 1}$ \\
\hline
\end{tabular}

Data expressed as frequency (percentage), mean (SD). APRI: AST to platelet ratio index; FIB-4: fibrosis-4; AST: aspartate transaminase; ALT; alanine transaminase; AFP: alpha fetoprotein; U/S: ultrasound; HCV RNA: hepatitis C virus ribonucleic acid. 
Regimens of therapy and sustained virological response among enrolled patients:

As regard regimens of therapy majority (76\%) of those patients with high AFP received triple therapy for three months in form of sofosbuvir, daclatasvir with weight based ribavirin while only $12(12 \%)$ patients from those with normal AFP received triple therapy. Majority (88\%) of those patients with normal AFP received dual therapy in form of sofosbuvir, and daclatasvir for three months while only 24 (24\%) patients from those with high AFP received dual therapy.

Majority (95\% of those with high AFP and 97\% of those with normal AFP) achieved sustained virological response while only five patients with high AFP and three patients with normal AFP failed to achieve sustained virological response.

\section{Frequency of hepatocellular carcinoma post-therapy} among studied groups (Tables 3 and 4):

A total 10/200 (5\%) patients of all enrolled patients developed HCC during follow up after therapy. It was found that frequency of HCC was significantly higher among those patients with high AFP in comparison to those with normal AFP.

Table (3): Frequency of hepatocellular carcinoma post-therapy among studied groups

\begin{tabular}{|l|c|c|c|}
\hline & $\begin{array}{c}\text { High } \\
\text { AFP } \\
(\mathbf{n = 1 0 0})\end{array}$ & $\begin{array}{c}\text { Normal } \\
\text { AFP } \\
(\mathbf{n = 1 0 0})\end{array}$ & $\begin{array}{c}\boldsymbol{P} \\
\text { value }\end{array}$ \\
\hline Development of & & & \\
HCC & $91(91 \%)$ & $99(97 \%)$ & $<0.01$ \\
No & $9(9 \%)$ & $1(1 \%)$ & \\
Yes &
\end{tabular}

Data expressed as frequency (percentage). AFP: alpha fetoprotein; HCC: hepatocellular carcinoma

Table (4): Characteristics of patients with hepatocellular carcinoma

\begin{tabular}{|c|c|c|c|c|c|c|c|}
\hline Case & Age & Sex & PVT & $\begin{array}{c}\text { Baseline } \\
\text { AFP }\end{array}$ & Time & $\begin{array}{c}\text { No of } \\
\text { HCC }\end{array}$ & $\begin{array}{c}\text { Size } \\
(\mathbf{c m})\end{array}$ \\
\hline $\mathbf{1}$ & 51 & Male & Yes & & 8 & $\mathbf{2}$ & $\begin{array}{c}\mathbf{2 * 4 /} \\
\mathbf{2 . 5} \mathbf{4}\end{array}$ \\
\hline $\mathbf{2}$ & 53 & Male & No & 12 & 4 & 1 & $2.5 * 5$ \\
\hline $\mathbf{3}$ & 51 & Male & Yes & 9 & 5 & 1 & $3.3 * 4$ \\
\hline $\mathbf{4}$ & 55 & Male & No & 22 & 6 & 1 & $1.8 * 2.5$ \\
\hline $\mathbf{5}$ & 55 & $\begin{array}{c}\text { Fema } \\
\text { le }\end{array}$ & Yes & & 7 & 1 & $2 * 4$ \\
\hline $\mathbf{6}$ & 46 & Male & No & 12 & 8 & 1 & $2.5 * 4.5$ \\
\hline $\mathbf{7}$ & 65 & Male & No & 23 & 6 & 1 & $2.7 * 3.3$ \\
\hline $\mathbf{8}$ & 56 & Male & No & 21 & 11 & 1 & $1.5 * 3.5$ \\
\hline $\mathbf{9}$ & 48 & Male & No & 19 & 10 & 1 & $2 * 4.5$ \\
\hline $\mathbf{1 0}$ & 55 & Male & No & 15 & 11 & 1 & $3 * 5.5$ \\
\hline PVT & & & & & & \\
\hline
\end{tabular}

PVT: portal vein thrombosis; AFP: alpha fetoprotein; HCC: hepatocellular carcinoma
Predictors of development of hepatocellular carcinoma following therapy (Table 5):

Based on the current study; the predictors for development of HCC following DAAs therapy were; liver cirrhosis, FIB-4, APRI, and AFP.

Table (5): Predictors of development of hepatocellular carcinoma following therapy

\begin{tabular}{|l|c|c|c|}
\hline & $\begin{array}{c}\text { Odds } \\
\text { ratio }\end{array}$ & $\begin{array}{c}\text { 95\% } \\
\text { confidence } \\
\text { interval }\end{array}$ & $\begin{array}{c}\boldsymbol{P} \\
\text { value }\end{array}$ \\
\hline $\begin{array}{l}\text { Age } \\
(>60 \text { years })\end{array}$ & 1.13 & $0.11-1.45$ & $>0.05$ \\
\hline $\begin{array}{l}\text { INF } \\
\text { experienced }\end{array}$ & 0.98 & $0.44-1.40$ & $>0.05$ \\
\hline $\begin{array}{l}\text { BMI } \\
\left(>25 \mathrm{~kg} / \mathrm{m}^{2}\right)\end{array}$ & 1.49 & $1.22-2.89$ & $>0.05$ \\
\hline $\begin{array}{l}\text { Liver } \\
\text { cirrhosis }\end{array}$ & 4.56 & $2.34-6.87$ & $<0.001$ \\
\hline $\begin{array}{l}\text { FIB-4 } \\
(>1.45)\end{array}$ & 1.45 & $1.34-3.03$ & $<0.001$ \\
\hline $\begin{array}{l}\text { APRI } \\
(>3.25)\end{array}$ & 1.98 & $1.07-3.87$ & $<0.001$ \\
\hline $\begin{array}{l}\text { AFP } \\
(>10 \mathrm{ng} / \mathrm{ml})\end{array}$ & 3.87 & $2.01-4.98$ & $<0.001$ \\
\hline APRI AST & plat & $\mathrm{ing}$ \\
\hline
\end{tabular}

APRI: AST to platelet ratio index; FIB-4: fibrosis-4; AFP: alpha fetoprotein; INF: interferon, BMI: body mass index

Performance of AFP, FIB-4 and APRI in prediction of HCC following DAAs therapy (Table 6 and figure 1):

The performance of AFP at cutoff point $>10$ $(\mathrm{ng} / \mathrm{ml})$, of FIB-4 at cutoff point > 1.45; and of APRI at cutoff point $>3.25$ are shown in table 6 and figure 1 .

Table (6): Performance of different parameters in prediction of $\mathrm{HCC}$

\begin{tabular}{|l|c|c|c|}
\hline \multicolumn{1}{|c|}{ Indices } & AFP & FIB-4 & APRI \\
\hline Sensitivity & $87 \%$ & $20 \%$ & $20 \%$ \\
\hline Specificity & $70 \%$ & $80 \%$ & $93.3 \%$ \\
\hline PPV & $59 \%$ & $87 \%$ & $60 \%$ \\
\hline NPV & $91 \%$ & $43 \%$ & $70 \%$ \\
\hline Accuracy & $75.7 \%$ & $60.1 \%$ & $68.7 \%$ \\
\hline Cutoff point & $\begin{array}{c}>10 \\
(\mathrm{ng} / \mathrm{ml})\end{array}$ & $>1.45$ & $>3.25$ \\
\hline $\begin{array}{l}\text { Area under } \\
\text { curve }\end{array}$ & 0.80 & 0.59 & 0.59 \\
\hline
\end{tabular}

PPV: positive predictive value; NPV: negative predictive value; APRI: AST to platelet ratio index; FIB-4: fibrosis-4; AFP: alpha fetoprotein; HCC: hepatocellular carcinoma; DAAs: direct acting antivirals 


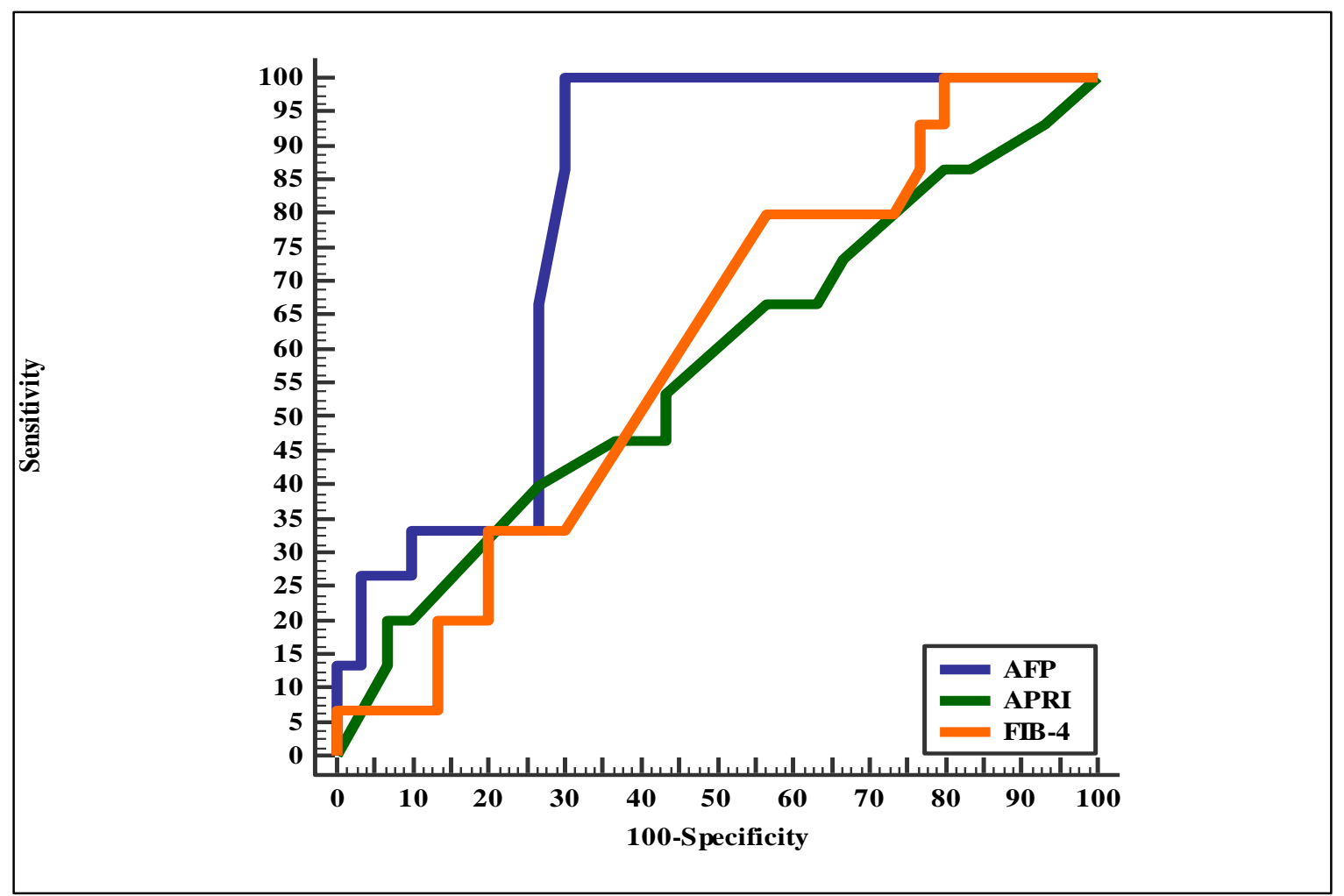

Figure (1): Diagnostic accuracy of AFP, FIB-4 and APRI in prediction of HCC following DAAs therapy. APRI: AST to platelet ratio index; FIB-4: fibrosis-4; AFP: alpha fetoprotein

\section{DISCUSSION}

In comparison to previous medications, SVR rates have increased to over $90 \%$ with very few documented side effects since the introduction of DAAs. DAA's introduction also permits individuals with decompensated cirrhosis to be treated. The longterm goal of DAA-induced SVR is to diminish fibrosis and chronic hepatitis $\mathrm{C}$ consequences, such as the development of $\mathrm{HCC}^{\left({ }^{(6)}\right.}$.

The current study enrolled 200 patients with chronic HCV infection. Those patients were followed for one year following DAAs therapy to assess the predictive value of baseline AFP in development of HCC following DAAs therapy. Those patients were divided into two groups either with high AFP $(>10$ $\mathrm{ng} / \mathrm{ml})$ or normal AFP $(<10 \mathrm{ng} / \mathrm{ml})$.

Both groups had insignificant differences as regard baseline data. Based on the current study, we found that patients with high AFP had significantly lower platelets count and higher APRI and FIB-4. This could be explained by higher frequency of patients with liver cirrhosis among those with high AFP (78\% vs. $12 \%)$.

Our study revealed that A total 10/200 (5\%) patients of all enrolled patients developed HCC during follow up after therapy. It was found that frequency of HCC was significantly higher among those patients with high AFP in comparison to those with normal AFP (9\% vs 1\%). Hamoir et al. ${ }^{(7)}$ also, studied 143 adult patients who have been treated with different regimens of DAA for $\mathrm{HCV}$-related chronic liver disease. Out of their patients, $4.2 \%$ developed HCC during one year duration of follow up. This frequency is comparable with the current result. In a previous study with median duration of follow up was 17 months after end of therapy, a total of 95/1045 (9.9\%) patients developed HCC. The discrepancy between this study and our study as regard frequency of development of HCC following DAAs may be because the authors of the latter study included cirrhotic patients and also, enrolled patients with previous history of $\mathrm{HCC}^{(8)}$. A review published by Waziry et al. ${ }^{(4)}$ summarizing the evidence on HCC occurrence and recurrence following DAA or IFN based therapy over the last 17 years showed a similar annual occurrence rate of HCC $(2.96 \%)$ in patients treated by DAA.

Based on the current study; the predictors for development of HCC following DAAs therapy were; liver cirrhosis, FIB-4, APRI and AFP. Also, we found that AFP had the best diagnostic accuracy for prediction of HCC following DAAs $(75.5 \%)$ in comparison to APRI (68.7\%) and FIB-4 (60.1\%). In consistent with the current study, Ogawa et al. (9) showed that age $>70$ (odds ratio $=2.39$ ), male sex (odds ratio $=2.07$ ), cirrhosis (odds ratio $=2.97$ ), serum albumin $<3.5 \mathrm{~g} / \mathrm{dL}$ (odds ratio= 2.72), and AFP $>7 \mathrm{ng} / \mathrm{ml}$ (odds ratio $=4.92)$ are considered risk factors for the development of HCC in patients received DAAs. In contrast to the current study, Conti et al. ${ }^{(10)}$ stated that baseline AFP level wasn't a risk HCC following DAAs.

Additional risk factors for development of HCC following DAAs was reported by Hamoir et al. ${ }^{(7)}$ who found that genotype 2 was associated with risk of HCC than patients with other genotypes (odds ratio $=2.8$ ) . The risk of HCC was also higher in patients with steatosis than in patients without (odds ratio=14.93). 
Akuta et al. ${ }^{(11)}$ concluded that although AFP levels at baseline > $10 \mathrm{ng} / \mathrm{ml}$ was higher among those with HCC, yet this was not approved with regression analysis.

In line with our findings, a previous study found that an AFP cut-off value $>6 \mathrm{ng} / \mathrm{ml}$ had the best sensitivity in prediction of HCC development ${ }^{(\mathbf{8})}$.

The main limitations of the current study included; 1) short term of follow up that was only one year post-therapy, 2) Identifying the carcinogenic process in this situation would almost probably necessitate actual studies gathering pathological and immunological data to look into tumour biology and the immune system changes that occur after $\mathrm{HCV}$ is removed abruptly with DAAs.

\section{CONCLUSION}

DAAs are effective and safe agents in management of patients with HCV infection. But long term follow up of those patients is very important because those patients are still at risk of developing HCC even after viral clearance.

\section{RECOMMENDATIONS}

Future studies with large sample size in multiple centers are warranted to confirm these findings.

Acknowledgments: none

Fund: none

Conflict of interest: None

\section{REFERENCES}

1. Dash S, Aydin Y, Widmer $\mathrm{K}$ et al. (2020): Hepatocellular carcinoma mechanisms associated with chronic HCV infection and the impact of direct-acting antiviral treatment. Journal of Hepatocellular Carcinoma, 7:45-49.

2. Younossi Z, Stepanova M, Jacobson I et al. (2018): Sofosbuvir and velpatasvir with or without voxilaprevir in direct-acting antiviral-naive chronic hepatitis $\mathrm{C}$ : patient-reported outcomes from POLARIS 2 and 3. Aliment Pharmacol Ther., 47: 259-267.

3. Arrieta O, Rodriguez-Diaz J, Rosas-Camargo $\mathrm{V}$ et al. (2006): Colchicine delays the development of hepatocellular carcinoma in patients with hepatitis virusrelated liver cirrhosis. Cancer, 107(8):1852-8.

4. Waziry R, Hajarizadeh B, Grebely J et al. (2017): Hepatocellular carcinoma risk following direct-acting antiviral HCV therapy: a systematic review, metaanalyses, and meta-regression. Journal of Hepatology, 67(6):1204-12.

5. Ballas M (1972): Yolk sac carcinoma of the ovary with alpha fetoprotein in serum and ascitic fluid demonstrated by immunoosmophoresis. Am J Clin Pathol., 57: 511-6.

6. Virlogeux V, Pradat P, Hartig-Lavie K et al. (2017): Direct-acting antiviral therapy decreases hepatocellular carcinoma recurrence rate in cirrhotic patients with chronic hepatitis C. Liver International, 37(8):1122-7.

7. Hamoir C, Horsmans Y, Stärkel P et al. (2021): Risk of hepatocellular carcinoma and fibrosis evolution in hepatitis $\mathrm{C}$ patients with severe fibrosis or cirrhosis treated with direct acting antiviral agents. Acta GastroEnterologica Belgica, 84:25-29.

8. Masetti C, Lionetti R, Lupo M et al. (2018): Lack of reduction in serum alpha-fetoprotein during treatment with direct antiviral agents predicts hepatocellular carcinoma development in a large cohort of patients with hepatitis C virus-related cirrhosis. Journal of Viral Hepatitis, 25(12):1493-500.

9. Ogawa E, Nomura H, Nakamuta M et al. (2020): Incidence of hepatocellular carcinoma after treatment with sofosbuvir-based or sofosbuvir-free regimens in patients with chronic hepatitis C. Cancers, 12(9):2602-5.

10. Conti F, Brillanti S, Buonfiglioli F et al. (2016): Safety and efficacy of direct-acting antivirals for the treatment of chronic hepatitis $\mathrm{C}$ in a real-world population aged 65 years and older. J Viral Hepat., 24: 454-463.

11. Akuta N, Kobayashi M, Suzuki F et al. (2016): Liver fibrosis and body mass index predict hepatocarcinogenesis following eradication of hepatitis $\mathrm{C}$ virus RNA by direct-acting antivirals. Oncology, 91(6):341-7. 